\title{
A mammosphere formation RNAi screen reveals that ATG4A promotes a breast cancer stem-like phenotype
}

Jonas Wolf ${ }^{1}$, Dyah Laksmi Dewi ${ }^{1}$, Johannes Fredebohm ${ }^{1}$, Karin Müller-Decker², Christa Flechtenmacher ${ }^{3}$, Jörg D Hoheisel ${ }^{1}$ and Michael Boettcher ${ }^{1 *}$

\begin{abstract}
Introduction: Breast cancer stem cells are suspected to be responsible for tumour recurrence, metastasis formation as well as chemoresistance. Consequently, great efforts have been made to understand the molecular mechanisms underlying cancer stem cell maintenance. In order to study these rare cells in-vitro, they are typically enriched via mammosphere culture. Here we developed a mammosphere-based negative selection shRNAi screening system suitable to analyse the involvement of thousands of genes in the survival of cells with cancer stem cell properties.

Methods: We describe a sub-population expressing the stem-like marker CD44 $/$ CD $24^{- \text {llow }}$ in SUM149 that were enriched in mammospheres. To identify genes functionally involved in the maintenance of the sub-population with cancer stem cell properties, we targeted over 5000 genes by RNAi and tested their ability to grow as mammospheres. The identified candidate ATG4A was validated in mammosphere and soft agar colony formation assays. Further, we evaluated the influence of ATG4A expression on the sub-population expressing the stem-like marker $\mathrm{CD}_{4} 4^{+} / \mathrm{CD}_{2} 4^{\text {low }}$. Next, the tumorigenic potential of SUM149 after up- or down-regulation of ATG4A was examined by xenograft experiments.
\end{abstract}

Results: Using this method, Jak-STAT as well as cytokine signalling were identified to be involved in mammosphere formation. Furthermore, the autophagy regulator ATG4A was found to be essential for the maintenance of a sub-population with cancer stem cell properties and to regulate breast cancer cell tumourigenicity in vivo.

Conclusion: In summary, we present a high-throughput screening system to identify genes involved in cancer stem cell maintenance and demonstrate its utility by means of ATG4A.

\section{Introduction}

Breast tumours, like many other solid tumours, consist of highly heterogeneous cell populations with varying phenotypic and functional properties [1]. Similar to the normal mammary gland, these populations include cells with luminal-epithelial, basal and stem-cell-like features [2]. Based on gene expression profiles, basal-like breast cancers have been associated with the surface marker expression $\mathrm{CD} 44^{+} / \mathrm{CD} 24^{-/ \text {low }}$ [3] while luminal epithelial cells have been associated with $\mathrm{CD} 24^{+} / \mathrm{CD} 44^{-}$expression $[4,5]$. Stem-like cells with tumour initiating capabilities

\footnotetext{
*Correspondence: m.boettcher@dkfz.de

'Division of Functional Genome Analysis, Deutsches Krebsforschungszentrum, Heidelberg, Germany

Full list of author information is available at the end of the article
}

have been found to be enriched in the $\mathrm{CD} 44^{+} / \mathrm{CD} 24^{-/ \text {low }}$ sub-population of basal breast carcinoma cells [6]. These stem-like cells or cancer stem cells (CSCs) are held responsible for metastasis formation $[7,8]$ and chemoresistance [9]. Further, it was found that $\mathrm{CD} 44^{+} / \mathrm{CD} 24^{-/ \text {low }}$ breast cancer cells exhibit epithelial-to-mesenchymal transition (EMT) features that might be responsible for their aggressive clinical behaviour [10]. EMT has long been recognised as an important programme for embryonic development [11] and has more recently been associated with breast CSC regulation [12,13]. It is hypothesised that differentiated cancer cells can become CSCs as a consequence of EMT, allowing them to migrate, metastasize and survive chemotherapy $[7,14]$. In line with these findings, CSCs have been connected to a mesenchymal phenotype [15], and it was shown that chemoresistant cells display not only

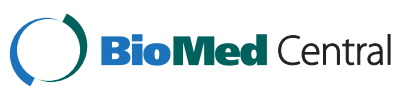


CSC but also mesenchymal features [14]. Due to the aggressive nature of CSCs, the identification of genes and pathways that they depend on is an active area of research, fuelled by the promise that combination of conventional chemotherapy with specific CSC inhibitors will increase therapeutic success rates [16].

A major restraint when studying stem cells as well as CSC is their rareness. One approach to enrich breast stem cells, which has become particularly popular over the past ten years, is culturing cells as mammospheres [17]. It was shown that rare, single-founder stem cells can form multicellular sphere structures under serum-free suspension conditions that are enriched for stem and early progenitor cells [17]. Later, it was also found that rare cancer cells possess the ability to form mammospheres enriched for highly tumourigenic $\mathrm{CSCs}$ of the $\mathrm{CD} 44^{+} / \mathrm{CD} 24^{-/ \text {low }}$ phenotype $[5,18]$. Moreover it was shown that cells enriched in mammospheres had passed through EMT and were chemoresistant [19] which are two properties typically attributed to CSCs [12]. Here, we utilised the enrichment of CSCs in mammospheres and developed a high-throughput a short hairpin RNA interference (shRNAi) screening system to assay the involvement of over 5,000 genes in the maintenance of a population of cells with CSC properties. The results give an insight into molecular mechanisms underlying CSC maintenance in mammospheres and attribute a previously unrecognised role in this process to the autophagy regulator ATG4A.

\section{Materials and methods}

\section{Adherent and mammosphere cell culture}

SUM149 cells were obtained from the Kuperwasser Laboratory (Tufts University, Boston) and are commercially available (Asterand, Royston, UK). Cells were cultured in Ham's F12 (Life Technologies, Darmstadt, Germany) with $5 \%$ calf serum, $5 \mu \mathrm{g} / \mathrm{ml}$ bovine insulin (Sigma-Aldrich, Taufkirchen, Germany), and $1 \mu \mathrm{g} / \mathrm{ml}$ hydrocortisone (Sigma-Aldrich). MDA-MB-231 and MCF-7 were cultured in DMEM (Life Technologies) with $10 \%$ calf serum. For mammosphere formation, $10^{4}$ cells $/ \mathrm{cm}^{2}$ cells were plated in an ultra-low attachment cell culture flask (Corning, Kaiserslautern, Germany) and cultured in MammoCult medium (StemCell Technologies, Grenoble, France). After 14 days, the mammospheres were counted and pictures were taken. For flow cytometric analysis, spheres were filtered through a $40-\mu \mathrm{m}$ cell strainer (Becton Dickinson, Heidelberg, Germany) and treated with Accutase (Sigma-Aldrich) to obtain a single cell suspension.

\section{Mammosphere formation RNAi screen}

The DECIPHER RNAi library Module 1 (Cellecta, Mountain View, USA) [20] was used at low multiplicity of infection $(\mathrm{MOI}=0.3)$ to transduce SUM-149 cells, followed by $48 \mathrm{~h}$ of selection with $2.5 \mu \mathrm{g} / \mathrm{ml}$ puromycin. Following 48 h recovery in antibiotic-free medium, $1.4 \times 10^{8}$ stably transduced cells were seeded into $180 \times 75 \mathrm{~cm}^{2}$ ultra-low attachment cell culture flask (Corning) and cultured in MammoCult (StemCell Technologies). After 14 days, mammospheres larger than $40 \mu \mathrm{m}$ were extracted by five individual rounds of filtration through $40-\mu \mathrm{m}$ mesh size cell strainers (Becton Dickinson). About $7 \times 10^{6}$ transduced cells were cultured adherently for the same period of time in Ham's F12 as a reference. Cells were passaged after reaching 80\% confluence. Genomic DNA from adherently cultured cells at the beginning (baseline) and the end of the screen $\left(t_{\text {adherent }}\right)$ as well as from pooled mammosphere samples $\left(t_{\text {sphere }}\right)$ was isolated using the DNeasy Blood and Tissue Kit (Qiagen, Hilden, Germany). Construct-specific barcode sequences were amplified under PCR conditions provided by the manufacturer of the DECIPHER library (Cellecta). Barcode sequences are 18 nucleotide-long DNA sequences that are unique for each of the 27,500 shRNA expression constructs in the DECIPHER library pool. Hence, they can be used as surrogate markers to quantify the number of cells expressing a certain shRNA in a pool of cells. PCR amplification of barcode sequences resulted in ready-to-load sequencing libraries including adaptor sequences for Illumina GA and HiSeq platforms. The barcodes were amplified and sequenced in duplicate on Illumina GAIIx machines and quantified using Barcode Deconvoluter software (Cellecta).

\section{Data analysis}

Two separate barcode read-count ratios were calculated. In order to identify shRNAs, which are toxic to adherent cells or mammospheres, the ratios $\left[\mathrm{t}_{\text {adherent }} /\right.$ baseline $]$ or $\left[\mathrm{t}_{\text {sphere }} /\right.$ baseline] were calculated, respectively. Results are shown in Additional file 1. Ratios from each set of shRNAs (5 to 6) targeting a particular gene were compared to ratios from a set of 21 negative control shRNAs targeting the gene Luciferase via unpaired, two-sided, unequal variance $t$-test statistics. Calculated mean fold changes from each set of shRNA expression constructs and corresponding $P$-values for every gene present in the library are shown in Additional file 2.

\section{Lentivirus-mediated RNAi}

For target validation, shRNA template sequences identified in the screen were synthesized individually (Sigma-Aldrich) and cloned into the pRSI9 vector backbone. Cloning and virus production were performed following the protocol provided by the manufacturer (Cellecta). Sequences were as follows: shATG4A-1 5'-ACCGGCAGATACAGATG AGTTGGTATGTTAATATTCATAGCATACCAGCTCA TCTGTATCTGTTTT-3'; shATG4A-2 5'-ACCGGCCC GGAAAGAAATAGAATAATGTTAATATTCATAGCAT TGTTCTATTTCTTTCCGGGTTTT-3'; shATG4A-3 5' ACCGGGCTGTTGTAATGAGGAAATGGGTTAATAT TCATAGCCCATTTCCTCATTGCAGCAGCTTTT-3' 
and shCTRL 5'-ACCGGATCACAGAATCGTCGTA TGTAGTTAATATTCATAGCTGCATACGACGATTC TGTGATTTTT-3'. For virus production, cloned shRNA plasmids were co-transfected with the packaging plasmids psPAX2 and pMD2.G into HEK293T cells. Viral supernatant was harvested $48 \mathrm{~h}$ post transfection and cleared from debris via centrifugation. Cells were transduced with lentivirus for $24 \mathrm{~h}$ in cell culture medium containing $8 \mu \mathrm{g} /$ ml polybrene (Sigma-Aldrich) and selected with $2.5 \mu \mathrm{g} / \mathrm{ml}$ puromycin (Sigma-Aldrich) for $48 \mathrm{~h}$. Following selection cells were recovered for $48 \mathrm{~h}$ in antibiotic-free culture medium.

\section{mRNA quantification}

Total RNA was isolated from cells or mammospheres using RNeasy Mini Kit (Qiagen). Reverse transcription and PCR were performed using the One Step Quantifast SYBR Green RT-PCR Kit (Qiagen) with a LightCycler 480 system (Roche, Mannheim, Germany). For target gene amplification, the QuantiTect Primer Assay (Qiagen) was used. Target gene expression was normalised to the expression of glyceraldehyde-3-phosphate dehydrogenase (GAPDH).

\section{Protein quantification}

To determine the protein concentration, cells were lysed in TBS containing 1\% Triton X-100, $10 \mathrm{mM} \mathrm{Na}_{3} \mathrm{VO}_{4}, 1 \mathrm{mM}$ $\mathrm{NaF}, 4 \mathrm{mM}$ ethylenediaminetetraacetic acid (EDTA), protease inhibitor mixture (Roche). the protein concentration was measured with the bicinchoninic acid (BCA) Protein Assay (Thermo Fisher Scientific, Bonn, Germany). Proteins were separated by SDS-PAGE and blotted onto a nitrocellulose membrane (GE Healthcare, Freiburg, Germany). The membrane was probed with antibodies; peroxidase-conjugated secondary antibodies detected the bands by ECL Plus (ThermoFisher Scientific). Antibodies were: antiATG4A (Gene'Tex, Irvine, USA) and anti-Tubulin (Abcam, Cambridge, UK).

\section{Flow cytometry}

vSingle cell suspension of adherent cells or spheres was stained with CD24-FITC, CD44-PE/Cy7 and EpCAMAPC (Becton Dickinson), E-cadherin-PE (Miltenyi Biotec, Bergisch Gladbach, Germany) and Vimentin-Alex488 (Cell Signaling, Danvers, USA). The cells were measured using a FACS-Canto-II (Becton Dickinson) and data were analysed using FlowJo software (Tree Star, Ashland, USA).

\section{Colony formation assay}

We suspended 2,500 cells $/ \mathrm{cm}^{2}$ in $0.3 \%$ agarose with MammoCult medium (StemCell Technologies) on a $0.8 \%$ agar base layer. The culture was covered with $0.5 \mathrm{ml} \mathrm{Mammo-}$ Cult medium and cultured for 14 days. For quantification, the wells were imaged using a microscope, and the colonies were analysed using ImageJ software.

\section{Microarray and gene expression analysis}

SUM149 cells were cultured adherently and under mammosphere formation conditions in biological triplicates for two weeks. Spheres were filtered using a $40-\mu \mathrm{m}$ cell strainer (Becton Dickinson) and RNA was isolated from spheres and adherent cells using RNeasy Mini Kit (Qiagen). RNA was analysed on HumanHT-12 v4 Expression BeadChip (Illumina, San Diego, USA) according to manufacturer instructions. Raw data were normalised and grouped using Chipster. Genes with significant gene expression changes $(P$ $<10^{-10}$ ) were used for pathway enrichment analysis using DAVID Functional Annotation Tool [21]. Data were uploaded to ArrayExpress [22] under the accession number E-MTAB-1553.

\section{MACS cell enrichment of sub-population}

The described sub-population of SUM149 cell was enriched by depletion of EpCAM-expressing cells using EpCAM MicroBead Kit (Miltenyi Biotec). The depletion was performed according to the manufacturer's protocol. Enrichment of $\mathrm{CD} 44^{+} / \mathrm{CD} 24^{\text {low }} / \mathrm{EpCAM}^{-/ \text {low }}$ cells was confirmed via fluorescent-activated cell sorting (FACS).

\section{Xenograft experiments}

Cells were transduced with plasmids expressing shATG4A1 and -2 (shATG4A), the ATG4A open reading frame (ATG4A-OE), or a non-silencing control (shCTRL). This was followed by a selection of transduced cells with puromycin. For each injection, $4 \times 10^{4}$ cells in $15 \mu \mathrm{l}$ PBS were mixed 1:1 (v/v) with Matrigel (BD Biosciences, Heidelberg, Germany) prior to injection into the second left thoracic mammary fat pad of 8- to 9-week-old NOD SCID gamma (NSG) female mice. Tumour growth was monitored over a period of 15 weeks and tumour size was determined twice a week using a caliper. Significance values from Kaplan-Meier plots were calculated using the Wilcoxon test and GraphPad Prism software. For tissue staining, tumours were collected and embedded into paraffin according to routine procedures. H\&E staining was done on $5-\mu \mathrm{m}$ paraffin sections. Studies were approved by the local ethics committee at Regierungspräsidium Karlsruhe (G74/11, G244/11).

\section{Results}

SUM-149 cell line contains a sub-population of cells with cancer stem-cell properties

Flow cytometry analysis of the triple-negative human breast cancer cell line SUM-149 revealed two distinct subpopulations of cells. As previously described [5], we confirmed the existence of a small sub-population (S-P) of cells expressing the stem-like marker signature $\mathrm{CD} 44^{+} / \mathrm{CD} 24^{\text {low }}$ (Figure 1A). It was found that $\mathrm{CD} 44^{+} / \mathrm{CD} 24^{\text {low }}$ cells also express low levels of the epithelial cell adhesion molecule EpCAM (Figure 1A). This CD $44^{+} / \mathrm{CD} 24^{\text {low }} / \mathrm{EpCAM}^{-/ \text {low }}$ population was previously demonstrated to have basal as 
A

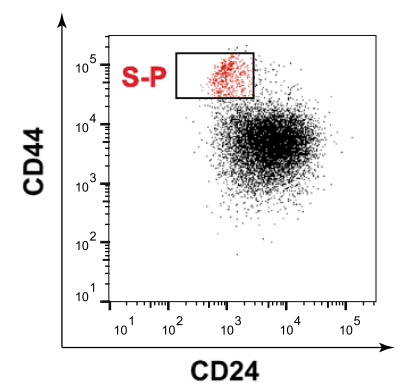

B

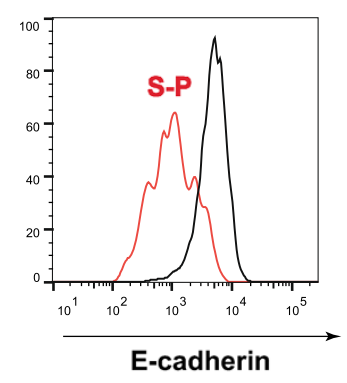

C

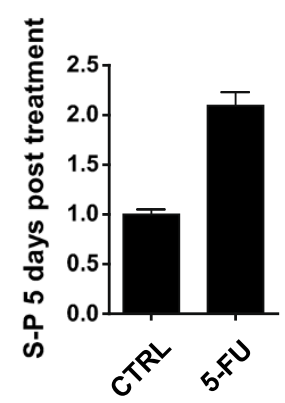

E

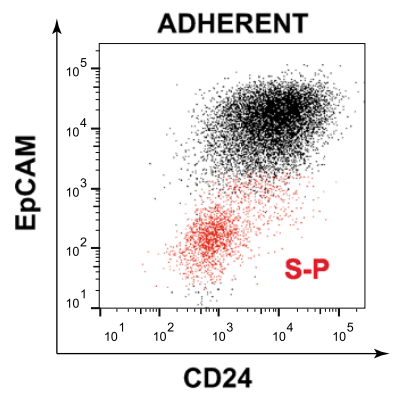

F

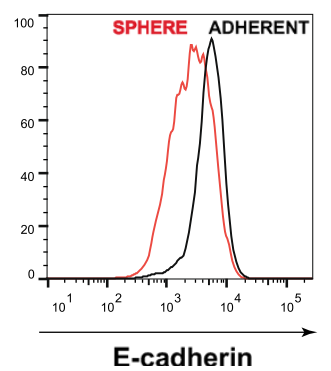

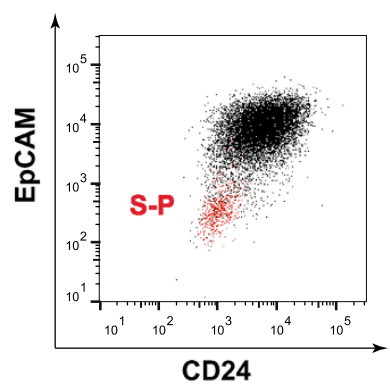

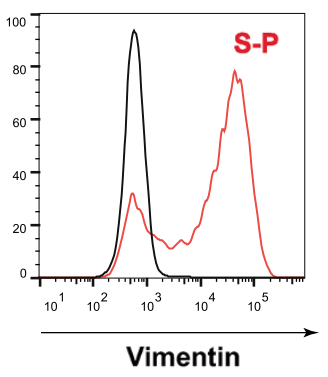

D
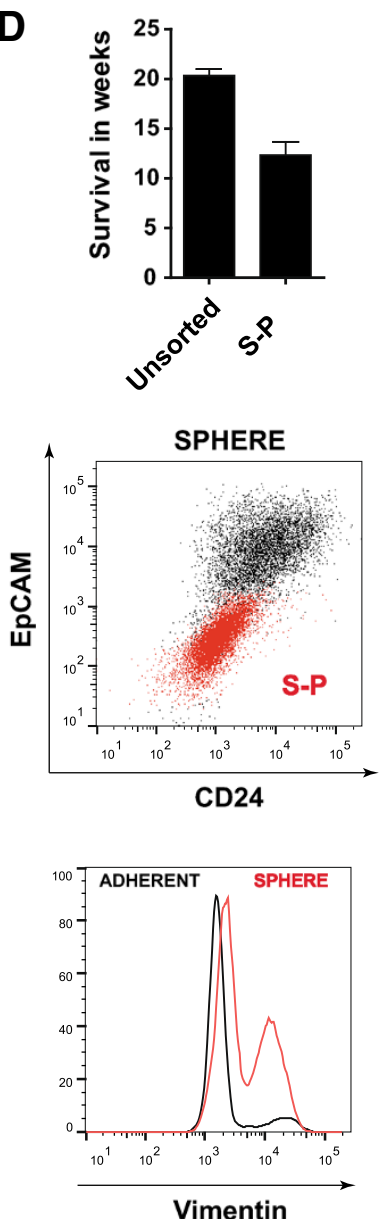

Figure 1 (See legend on next page.) 
well as stem-like features, while the opposing CD44\% $\mathrm{CD}_{2} 4^{+} / \mathrm{EpCAM}^{+}$population was described to be luminal [23]. To further examine both populations for epithelial or mesenchymal phenotypes, the expression of two markers commonly used to detect EMT, namely Ecadherin [24] and vimentin [25], was analysed in both populations. It was shown that cells from the subpopulation were almost completely negative for the epithelial marker E-cadherin and expressed higher levels of the mesenchymal marker vimentin (Figure 1B) when compared to the luminal population. Moreover, five days treatment of SUM-149 cells with the chemotherapeutic drug 5 '-fluorouracil $\left(5^{\prime}\right.$-FU) resulted in an enrichment of cells from the sub-population (Figure 1C). Last, sorted cells from the sub-population injected subcutaneously into NSG mice formed tumours much more rapidly than unsorted SUM-149 cells (Figure 1D). Taken together, the characterised sub-population of cells displays several CSC properties, namely expression of stem-like surface markers, passage through EMT, and chemoresistance, as well as increased tumourigenicity in-vivo [12].

\section{Cells with cancer stem-cell properties accumulate in mammospheres}

It was previously shown that cancer cells with stem-like characteristics become strongly enriched in mammospheres [17]. This enrichment is a result of their ability to grow independently of anchorage, a condition under which most cancer cells undergo anoikis [26]. The resistance to anoikis is commonly attributed to cells that have undergone EMT $[13,26]$. As shown in Figure 1E, flow cytometry analysis of mammosphere-derived SUM-149 cells revealed an enrichment of the $\mathrm{CD} 44^{+} / \mathrm{CD} 24^{\text {low }} / \mathrm{EpCAM}^{-/ \text {low }}$ population compared to adherent cultured cells. In accord with the enrichment of this sub-population in mammospheres, it was found that spheres express lower levels of E-cadherin and higher levels of vimentin when compared to adherent cells (Figure 1F). These data clearly confirmed that a subpopulation of cells with CSC properties became enriched during mammosphere formation. Therefore, targeting the survival of these cells should lead to impaired sphere formation. Based on this hypothesis, we established a screening system for the identification of genes that are specifically involved in mammosphere formation.

\section{Negative selection shRNAi screen for specific regulators of mammosphere formation}

SUM-149 cells were transduced with the pooled, lentiviral DECIPHER library Module 1 under conditions that ensured a maximum of one integration event per cell. The module targets 5,045 genes for knockdown by 5 to 6 dissimilar shRNA sequences per target gene, adding up to a total of 27,500 shRNA expression constructs that integrated into the genome of the host cells. In order to identify genes whose inhibition selectively impairs the formation of mammospheres, cells were sub-cultured under two distinct conditions. One fraction of cells was cultured adherently and a second fraction was cultured under mammosphere formation conditions (Figure 2A). After fourteen days in suspension culture, 1.3 percent of cells formed mammospheres (Figure 3B) with an average size of $120 \mu \mathrm{m}$ (Figure 3C). A total of 1.8 million mammospheres or 66 spheres per shRNA were analysed in the screen. To identify shRNAs with expression that impaired sphere formation, mammospheres larger than $40 \mu \mathrm{m}$ were collected, and smaller spheres and single cells were discarded (Figure 2A). From cells at the beginning of the screen (baseline), cells cultured adherently for fourteen days ( $t_{\text {adherent }}$ ) and mammospheres larger $40 \mu \mathrm{m}$ ( $\left.\mathrm{t}_{\text {sphere }}\right)$, barcode sequences were recovered using PCR and quantified using next-generation sequencing. Each barcode sequence stands for a particular shRNA expression construct. Figure 2B shows barcode read-count ratio distributions from spherecultured cells relative to the baseline. Corresponding values are given in Additional file 1. Based on those values, the impact of every single gene on adherent proliferation as well as mammosphere formation was determined and the results are shown in Additional file 2. In a first analysis step, a set of 1,015 genes was identified the inhibition of which significantly impaired the adherent survival of cells $(P<0.01)$. Pathway enrichment analysis using the DAVID Functional Annotation Tool [21] revealed highest enrichment of identified genes in Kyoto Encyclopedia of Genes and Genomes (KEGG) pathways related to proteasomal and ribosomal function (Table 1A). Although inhibition of the majority of those genes also impaired mammosphere formation, they cannot be considered to inhibit this process selectively. Consequently, 
A

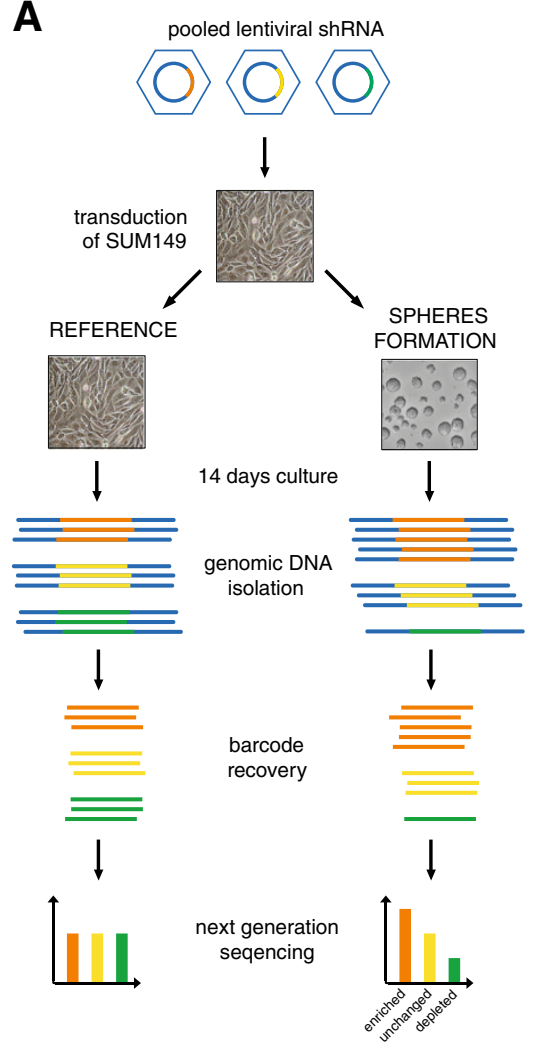

B

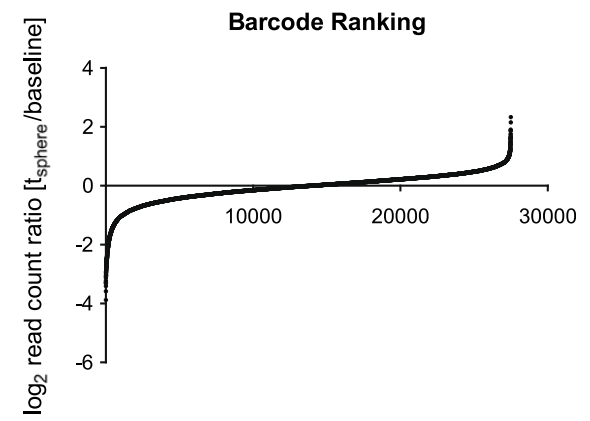

C

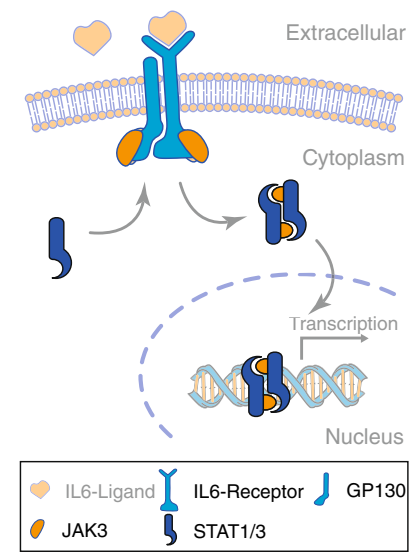

Figure 2 Negative selection mammosphere formation shRNAi screen. (A) Schematic, illustrating layout of pooled RNAi screen. Cells were transduced with the lentiviral DECIPHER RNAi library pool at low multiplicity of infection and cultured for fourteen days under adherent or suspension conditions, respectively. At the end of the screen, adherent cells and mammospheres $>40 \mu \mathrm{m}$ were harvested. Using next-generation sequencing of barcodes, the abundance of each shRNA expression construct in the pool was determined at the beginning of the screen (baseline) and from adherently cultured cells and mammospheres at fourteen days post seeding. Colour scheme: red: toxic shRNA; yellow: shRNA differentially inhibiting sphere formation; green: shRNA differentially activating sphere formation. (B) Barcode ranking. Shown are $\log _{2}$ ( $t_{\text {sphere/baseline) read-count }}$ ratios for all 27,500 shRNA expression constructs analysed in the screen. (C) Selected candidate genes involved in Janus kinase (Jak)-signal transducers and activators of transcription (STAT) Jak-STAT signalling.

in a second analysis step, only genes that impaired mammosphere formation $(P<0.01)$ but had no impact on adherent proliferation $(P>0.1)$ were used for pathway enrichment analysis. Pathway analysis showed the highest enrichment of candidate genes in Janus kinase (Jak)signal transducers and activators of transcription (STAT) and cytokine signalling followed by mTOR and several cancer-related signalling pathways (Table 1B). Genes associated with each pathway are shown in Additional file 3. As an example, five identified key regulators acting in Jak-STAT signalling are summarised in the scheme shown in Figure 2C.

\section{Mammospheres express high levels of lysosomal and oxidative phosphorylation genes}

In order to further investigate molecular differences between mammospheres and adherently cultured cells, gene expression profiles were compared; the results of a pathway enrichment analysis are summarized in
Additional file 4. Genes involved in cell cycle regulation $\left(\mathrm{P}=2 \times 10^{-20}\right)$ as well as DNA replication $\left(\mathrm{P}=2 \times 10^{-14}\right)$ were found to be down-regulated in mammospheres, which is in accordance with the reduced growth rate that cells exhibit under serum-free suspension conditions. Interestingly, strongest enrichment of up-regulated genes was seen for lysosome related genes $(\mathrm{P}=2 \times$ $10^{-18}$ ) and genes involved in oxidative phosphorylation $\left(\mathrm{P}=3 \times 10^{-14}\right)$ indicating a requirement of lysosomal activity and energy generation under sphere forming conditions.

\section{ATG4A is upregulated in mammospheres}

Two candidate genes identified by the screen to be necessary for mammosphere formation were the regulators of autophagy, ATG4A and ATG4B. It was further found that mRNA and protein levels of ATG4A, but not ATG4B, were elevated in spheres when compared to adherently cultured cells (Figure 4A). Together these 
A

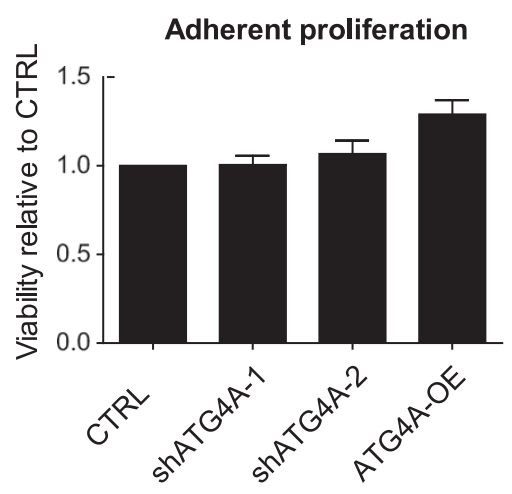

C

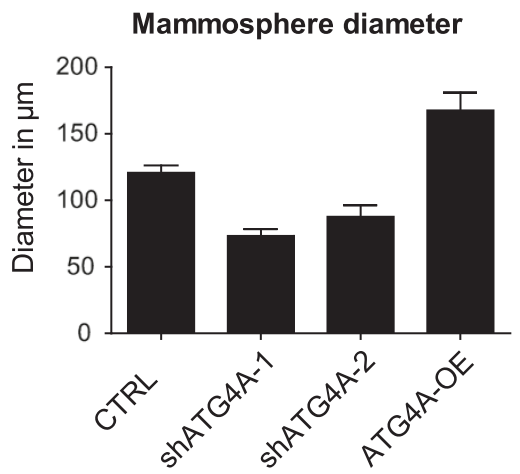

D

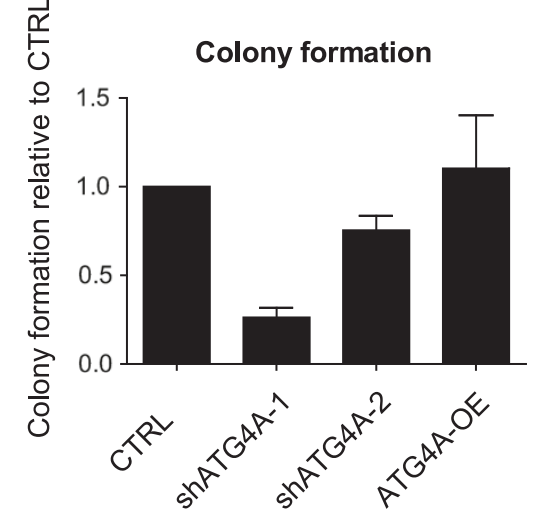

B
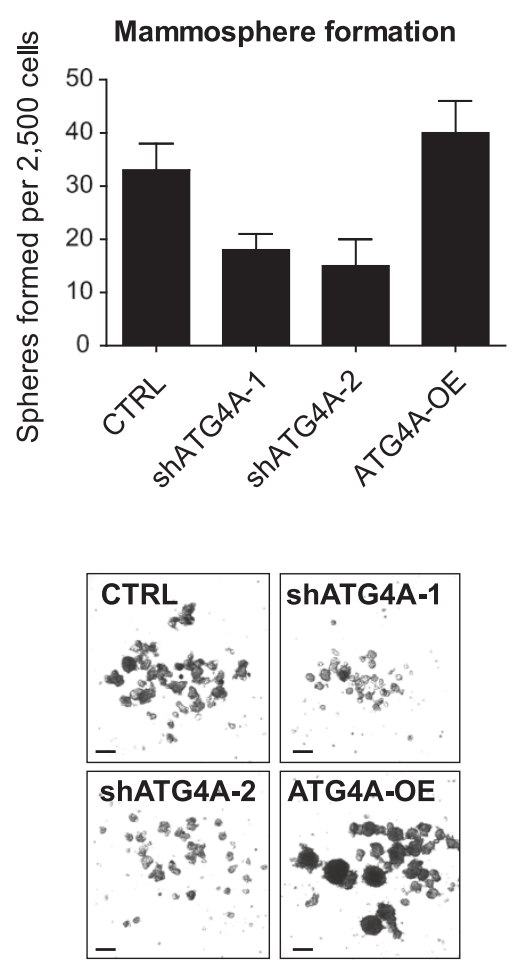

E

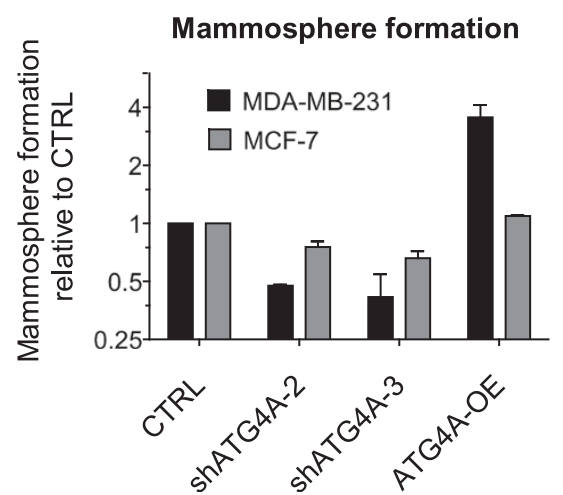

Figure 3 ATG4A expression regulates mammosphere formation in breast cancer cell lines. (A) Viability of SUM-149 cells cultured under adherent conditions with ATG4A inhibition or overexpression. (B) Number of mammospheres formed fourteen days post seeding 2,500 SUM-149 cells in serum-free suspension conditions. (C) Average size of SUM-149 mammospheres fourteen days post seeding and representative images of sphere numbers and sizes. Scale bars are $200 \mu \mathrm{m}$. (D) Relative number of colonies in soft agar fourteen days post seeding of SUM-149 cells. (E) Relative number of mammospheres at fourteen days post seeding of basal MDA-MB-231 or luminal MCF-7 cells with inhibited (shATG4A) or increased ATG4A expression (ATG4A-OE). CTRL, control.

findings implicated an important function for ATG4A during mammosphere formation. Hence, this gene was selected for further investigations. In order to analyse the impact of ATG4A on sphere formation and maintenance of cells with a CSC phenotype, two different shRNA sequences identified by the screen as well as the open reading frame of ATG4 $A$ were cloned into expression vectors. As shown in Figure 4B, the expression of both shRNAs reduced ATG4A mRNA levels by 4fold, whereas ATG4A overexpression increased mRNA levels to over 100 -fold. Concurrently, ATG4A protein levels were found to be reduced following expression of both shRNAs and increased for ATG4A overexpression (Figure 4C). Hence, these expression constructs represent efficient tools to artificially modulate ATG4A expression. 
Table 1 Pathway enrichment analysis of candidate genes

\begin{tabular}{|c|c|c|}
\hline KEGG pathway & Fold enrichment & $P$-value \\
\hline \multicolumn{3}{|l|}{ A } \\
\hline hsa03050:Proteasome & 3.38 & 1.41E-08 \\
\hline hsa03010:Ribosome & 3.89 & $2.28 E-06$ \\
\hline hsa04114:Oocyte meiosis & 1.77 & $1.64 E-03$ \\
\hline $\begin{array}{l}\text { hsa04914:Progesterone-mediated oocyte } \\
\text { maturation }\end{array}$ & 1.71 & $5.03 E-03$ \\
\hline hsa03040:Spliceosome & 2.39 & $8.61 E-03$ \\
\hline hsa05110:Vibrio cholerae infection & 1.86 & $1.55 E-02$ \\
\hline hsa04110:Cell cycle & 1.49 & $1.76 E-02$ \\
\hline hsa05016:Huntington's disease & 1.49 & $1.76 E-02$ \\
\hline hsa03020:RNA polymerase & 2.27 & 1.96E-02 \\
\hline hsa00970:Aminoacyl-tRNA biosynthesis & 1.97 & $2.08 E-02$ \\
\hline hsa00730:Thiamine metabolism & 3.57 & $3.30 E-02$ \\
\hline hsa04260:Cardiac muscle contraction & 1.96 & $3.80 E-02$ \\
\hline hsa00240:Pyrimidine metabolism & 1.52 & 4.51E-02 \\
\hline hsa00020:Citrate cycle (TCA cycle) & 1.90 & 4.80E-02 \\
\hline \multicolumn{3}{|l|}{ B } \\
\hline hsa04630:Jak-STAT signaling pathway & 2.05 & $1.76 E-03$ \\
\hline $\begin{array}{l}\text { hsa04060:Cytokine-cytokine receptor } \\
\text { interaction }\end{array}$ & 1.67 & $7.08 E-03$ \\
\hline hsa05215:Prostate cancer & 2.22 & $8.50 E-03$ \\
\hline hsa04150:mTOR signaling pathway & 2.72 & 1.47E-02 \\
\hline hsa05223:Non-small cell lung cancer & 2.49 & $1.61 E-02$ \\
\hline hsa05200:Pathways in cancer & 1.48 & $1.96 E-02$ \\
\hline hsa04510:Focal adhesion & 1.70 & $2.22 E-02$ \\
\hline hsa04062:Chemokine signaling pathway & 1.63 & 3.91E-02 \\
\hline hsa05216:Thyroid cancer & 3.04 & $4.16 E-02$ \\
\hline hsa04640:Hematopoietic cell lineage & 1.88 & 4.97E-02 \\
\hline
\end{tabular}

A, Kyoto Encyclopedia of Genes and Genomes (KEGG) pathway enrichment analysis was performed for genes essential for the survival of SUM-149 cells under adherent conditions; B, KEGG pathway enrichment analysis was done for genes specifically involved in mammosphere formation but not adherent cell survival. Jak-STAT, Janus kinase-signal transducers and activators of transcription.

\section{Modulation of ATG4A specifically regulates mammosphere formation}

To investigate whether regulation of ATG4A specifically regulates mammosphere formation, the impact of ATG4A modulation on the adherent proliferation, sphere formation and sphere diameter of SUM-149 cells was determined (Figure $3 \mathrm{~A}-\mathrm{C}$ ). It was found that inhibition of ATG4 $A$ had no impact on cell viability under adherent culture conditions illustrating that ATG4 $A$ is not an essential gene for the bulk of SUM-149 cells (Figure 3A). Yet the inhibition of ATG4A led to a decrease in sphere number and size. On average, 33 mammospheres formed from 2,500 cells $(1.3 \%)$ seeded under serum-free suspension conditions. Inhibition of ATG4A reduced this figure to 18

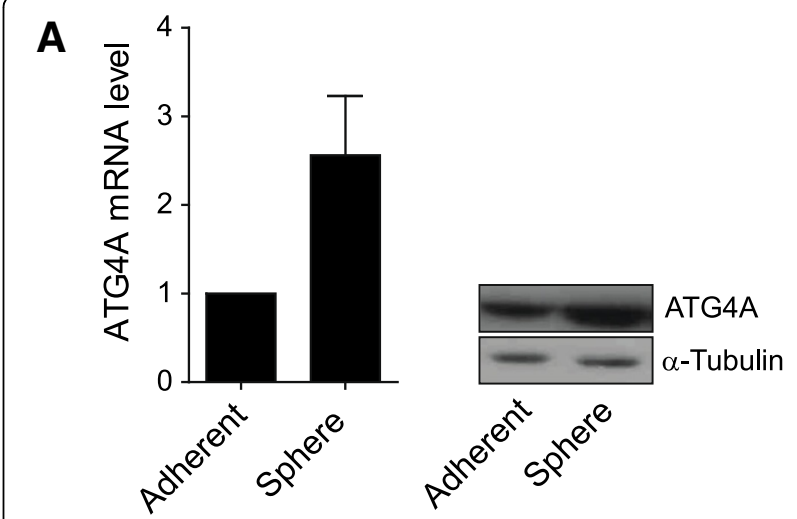

B

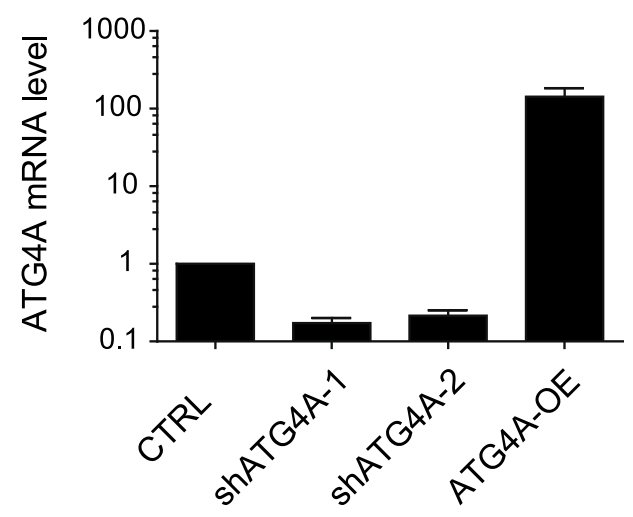

C

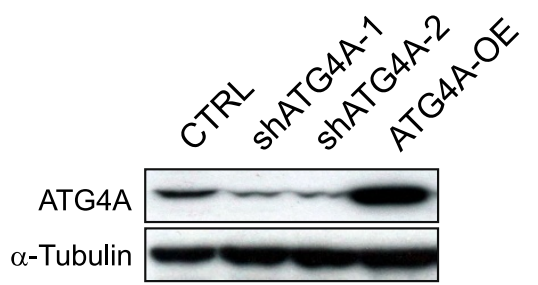

Figure 4 ATG4A expression levels in SUM-149 cells. (A) ATG4A mRNA and protein level in cells cultured adherently or as mammospheres. (B) Residual mRNA level of ATG4A following inhibition (shATG4A-1/-2) or overexpression (ATG4A-OE). (C) Residual protein level of ATG4A following inhibition or overexpression. CRTL, control.

and 15 spheres, respectively, and overexpression increased the number of spheres formed to 40 (Figure 3B). Mammospheres had an average diameter of $120 \mu \mathrm{m}$ at fourteen days post seeding of control cells. Inhibition of ATG4A reduced sphere size to $73 \mu \mathrm{m}$ or $88 \mu \mathrm{m}$, respectively, and ATG4 $A$ overexpression resulted in significantly larger spheres of $168 \mu \mathrm{m}$ (Figure 3C). Representative images of mammospheres following ATG4 $A$ knockdown or overexpression for fourteen days are shown in Figure 3C. In addition to sphere formation, the colony formation capacity of SUM-149 cells seeded in soft agar was determined after up- or down-regulation of ATG4A. As shown in Figure 3D, inhibition of ATG4A reduced the number of 
colonies formed, and overexpression slightly increased it. Further, the impact of ATG4A expression on sphere formation of breast cancer cell lines from different subtypes, namely basal MDA-MB-231 (CD44 $4^{+}$CD24 $)$and luminal MCF-7 cells (CD44 $/ 4^{-} 2_{2}^{+}$) [5] was analysed. MDA-MB-231 is a highly metastatic cell line with a high tumourigenicity compared to the non-invasive MCF-7 [27]. It was found that ATG4A inhibition reduced sphere formation in MDA-MB-231 cells, whereas its overexpression led to a dramatic increase (Figure 3E). Decreased sphere formation, although to a lesser extent, was also detected in luminal MCF-7 cells following ATG4 $A$ inhibition.

\section{ATG4A expression maintains sub-population of cells with cancer stem-cell phenotype}

In order to determine the impact of ATG4 $A$ expression on the sub-population of cells with CSC properties described above, CD24/EpCAM levels were compared between control cells (CTRL) and cells with reduced (shATG4A) or increased ATG4A expression (ATG4A-OE). Under adherent culture conditions, inhibition of ATG4A was found to reduce the sub-population whereas its overexpression increased it (Figure 5A). The contribution of ATG4A to the maintenance of this sub-population became even more evident in SUM-149 cells cultured as mammospheres (Figure 5B). Moreover, in mammospheres it was confirmed that ATG4A modulation changed mRNA expression levels of CDH1 and VIM. In line with the reduced sub-population following ATG4A inhibition, CDH1 levels were found to be increased and VIM levels decreased while the opposite was found for ATG4A overexpression (Figure 5C and 5D).

\section{Modulation of ATG4A regulates tumourigenic potential of SUM-149 cells in vivo}

ATG4 $A$ regulates mammosphere formation in several breast cancer cell lines as well as the maintenance of a sub-population with CSC properties. However, we wondered if it also regulates the tumourigenicity of cancer cells under physiological conditions. To answer this question, SUM-149 cells with inhibited ATG4A expression (shATG4A), cells overexpressing ATG4A (ATG4A-OE) and control cells (CTRL) were injected into the mammary fat pad of NSG mice. Tumour formation was monitored over a period of 15 weeks. As shown in Figure 6A, ATG4A overexpression significantly accelerated tumour formation $(P<0.01)$ whereas knockdown caused a reduced tumour burden $(P<0.05)$ when compared to control cells. Furthermore, at 15 weeks post injection, $100 \%$ of animals from the control group, but only $50 \%$ from the ATG4A knockdown group, had developed a tumour (Figure 6A). Analysis of H\&E-stained tissue sections revealed limited and circumscribed necrosis in control tumours, whereas
ATG4A overexpressing tumours displayed extensive and diffuse necrotic areas (Figure 6B). Tumour necrosis is generally associated with rapid tumour growth and was reported as an indicator of poor prognosis in breast cancer [28]. Moreover, the necrotic areas in ATG4Aoverexpressing tumours displayed strongly elevated levels of inflammation as judged by the staining of neutrophil granulocytes (Figure 6B, insert). In line with these findings, so-called smouldering inflammation in tumours has recently been described to promote malignant progression $[29,30]$. Taken together, ATG4A overexpression leads to an increased tumourigenicity of SUM-149 cells in NSG mice and to the development of tumours with a highly aggressive phenotype.

\section{Discussion}

CSCs are rare cells that are suspected to be responsible for tumour recurrence, formation of metastases and chemoresistance [7-9]. The rareness of these cells makes it particularly hard for researchers to study their function. To date, the only functional possibility to enrich breast CSCs with tumour-initiating properties in vitro is to culture them as mammospheres [17,18,31]. We found that SUM-149 mammospheres were enriched for cells that expressed a surface marker signature typical for stemlike breast cancer cells (Figure 1E), passed through EMT (Figure $1 \mathrm{~B}$ and $1 \mathrm{~F}$ ), were chemoresistant (Figure $1 \mathrm{C}$ ) and more tumourigenic in NSG mice (Figure 1D). These are properties typically attributed to breast CSCs [12]. Although under adherent conditions this sub-population accounted for approximately $6 \%$ of the total population (Figure 5A), it became enriched 5-fold in mammospheres (Figure 5B).

Here, we exploited this enrichment to establish a highthroughput pooled RNAi screening system suitable to identify genes that are specifically involved in the maintenance of those rare cells with CSC properties. The system is based on the comparison of two separate RNAi screens performed under (i) adherent and (ii) mammosphere culture conditions (Figure 2A). With the first screen, genes essential for the survival of the total cell population were identified. The second screen identified genes important for sphere formation and hence, served as a surrogate screen to identify genes that are important for the maintenance of cells with CSC properties. Subtractive analysis finally revealed genes that are primarily important for the survival of cells with CSC properties. The identified genes were used for a pathway enrichment analysis, which returned a number of cancer-related pathways and regulatory processes (Table 1B). In total 22 candidate genes were found to be associated with the Jak-STAT signalling pathway (KEGG), making it the most significant pathway identified $(P=0.00176)$. A schematic presentation of some of the identified candidate genes acting in the 
A
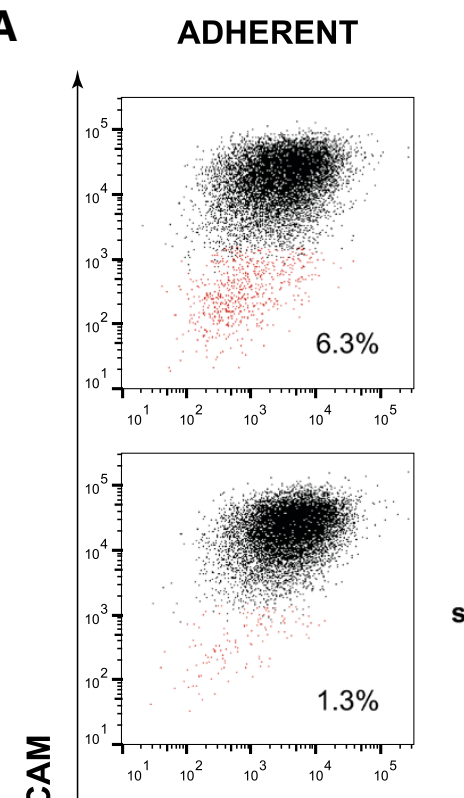

CTRL

B
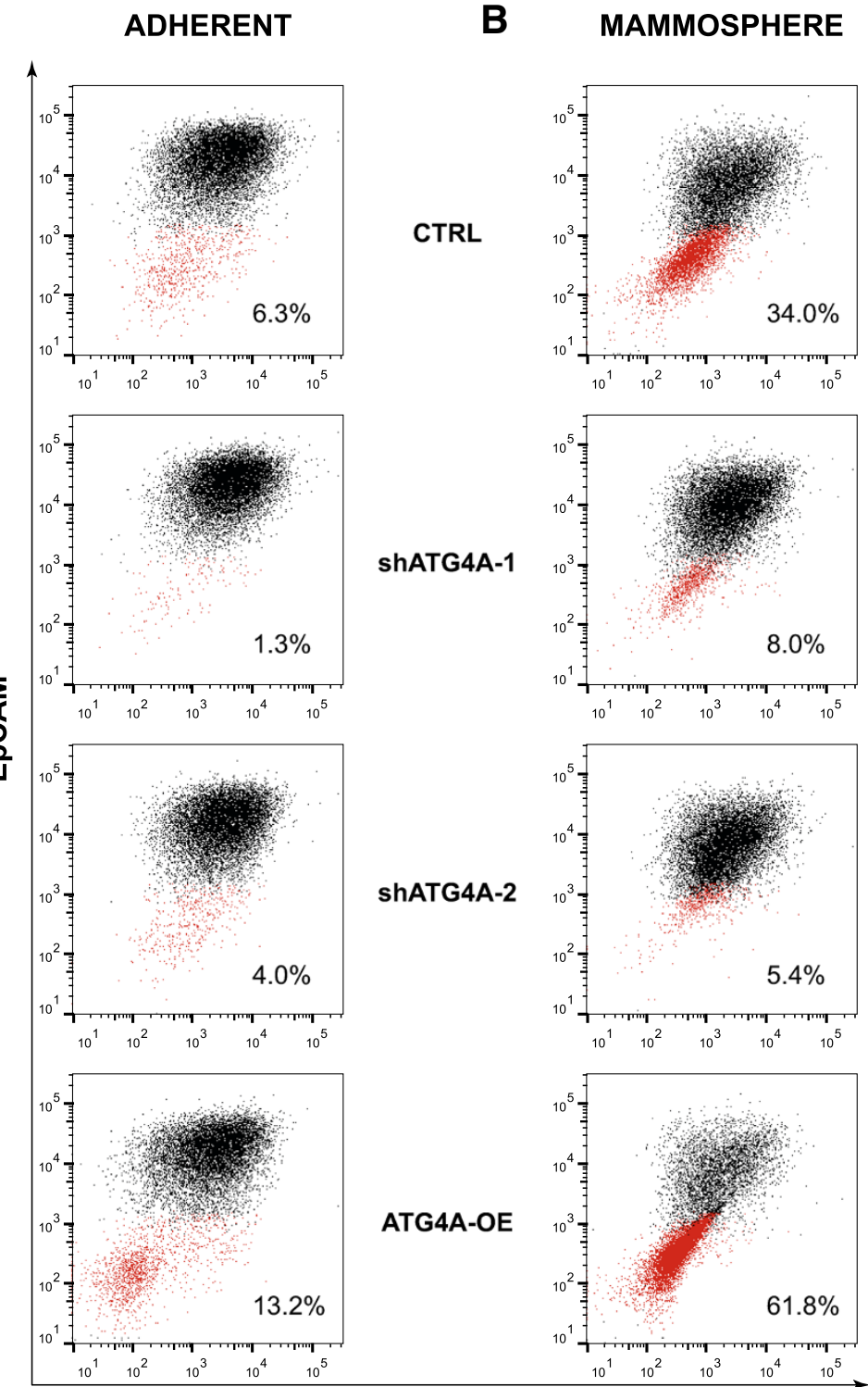

ATG4A-OE
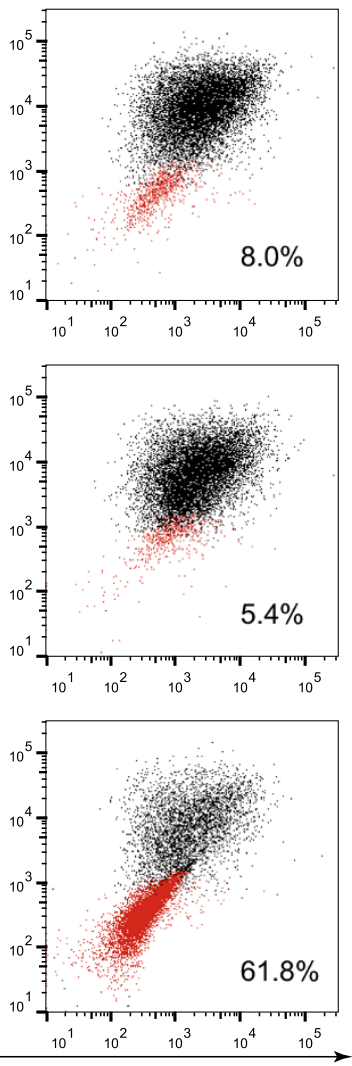

CD24

C

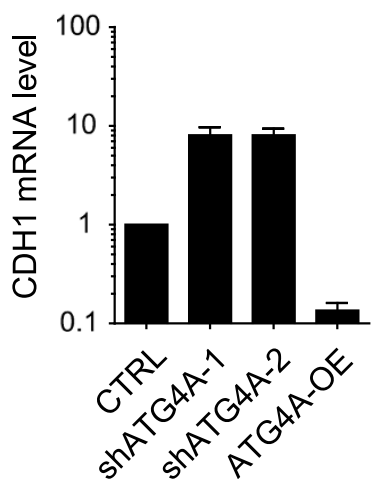

D

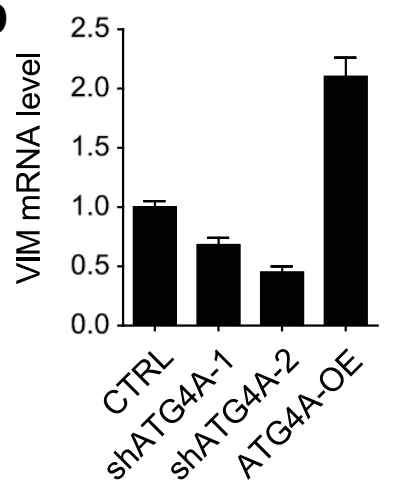

Figure 5 ATG4A expression regulates maintenance of sub-population with cancer stem-cell (CSC) properties. Flow cytometry analysis of EpCAM/CD24 expression in SUM-149 cells following ATG4A modulation under (A) adherent and (B) mammosphere formation conditions. (C) CDH1 mRNA level following ATG4A modulation. (D) VIM mRNA level following ATG4A modulation. CRTRL, control. 


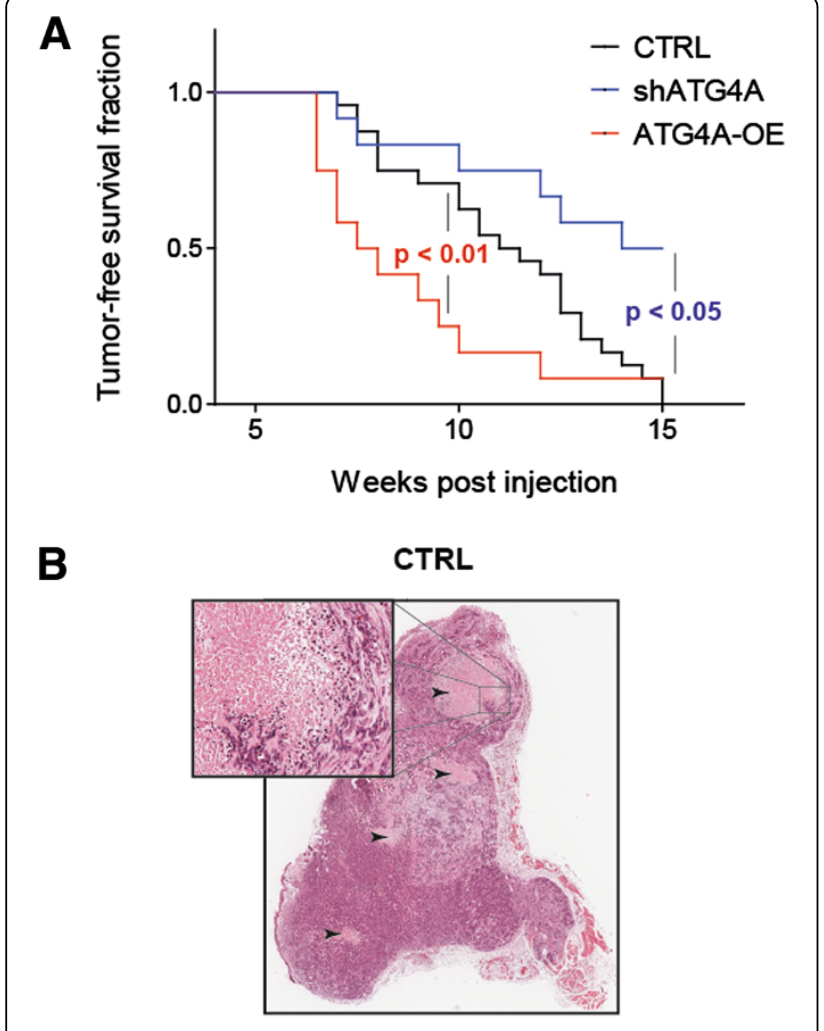

ATG4A-OE

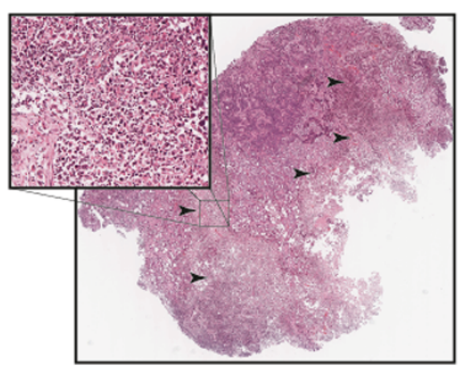

Figure 6 ATG4A expression regulates tumourigenicity of SUM-149 cells. (A) Tumour-free survival of NOD SCID gamma mice, following orthotopic injection of 40,000 SUM-149 cells with reduced ATG4A levels (shATG4A), increased ATG4A levels (ATG4A-OE) or control cells (CTRL). The indicated $P$-values were calculated using the Wilcoxon test. (B) Representative H\&E staining of sections from tumours derived from SUM-149 cells with increased ATG4A expression (ATG4A-OE) or CTRL respectively. Per group, $n>10$ sections were analysed. Control tumours show few circumscribed necrotic areas with few signs of inflammation, whereas ATG4A-overexpressing tumours exhibit extensive diffuse and strongly inflamed necrotic areas. Arrowheads indicate necrotic areas. Inserts show enlarged necrotic example areas with different degrees of inflammation.

Jak-STAT pathway is shown in Figure 2C. It is known that cytokine signalling via the IL6 receptor, GP130, JAK3, STAT1 and STAT3, as identified in our screen, is a regulator of breast CSC self renewal and differentiation [32,33]. Further, activated Jak-STAT signalling is essential for the survival of $\mathrm{CD} 44^{+} / \mathrm{CD} 24^{-/ \text {low }}$ stem-like breast cancer cells
[34] and was shown to play an important role during mammosphere formation [35]. Last, STAT3 was identified by another RNAi screen to be a critical player in mammosphere formation and self-renewal of breast CSCs [36]. Taken together, these findings confirm the utility of the presented screening system to identify processes with specific relevance to the maintenance and expansion of CSCs.

Despite the advantages of a functional enrichment, culturing of cells as mammospheres also has some drawbacks when performing a high-throughput screen. For the analysis of the screen, we pooled all spheres bigger than $40 \mu \mathrm{m}$. Therefore, we could not distinguish between sphere size and number of spheres. Large spheres are believed to consist of more differentiated cells or early progenitors than smaller spheres. Another concern might be the formation of spheres because of cell aggregation instead of clonal growth. To overcome this hurdle, we chose an appropriate cell density to avoid any sphere fusion. Moreover, we validated our candidates in semi-solid soft agar colony formation assays that guarantee clonal sphere growth.

Besides Jak-STAT signalling, a number of previously uncharacterized candidate genes were identified in this screen, one of which was the positive regulator of autophagy, ATG4 $A$. Autophagy is a lysosome-dependant degradation pathway allowing cells to remove macromolecules and damaged organelles in order to survive stress conditions $[37,38]$. Interestingly, it was recently published that autophagy promotes the undifferentiated stem-like $\mathrm{CD} 44^{+} / \mathrm{CD} 24^{- \text {llow }}$ phenotype in breast cancer cells [39] and further evidence for the involvement of autophagy in cancer stem-like cell maintenance as well as their differentiation is accumulating rapidly [40-43]. ATG4A is a redox-regulated cysteine protease [44]. ATG4A can cleave ATG8 near its C-terminus allowing the conjugation of ATG8 to phosphatidylethanolamine and subsequently to the membrane of the autophagosome [44]. In a second reaction, ATG4 can delipidate ATG8, releasing it from the autophagosomal membrane $[44,45]$. This cleavage marks a final step in autophagy and allows the fusion of autophagosome and lysosome [46,47]. The emerging role of autophagy in cancer stem cell maintenance together with the activation of lysosomal gene expression (Additional file 4) and upregulation of ATG4A (Figure 4A) in mammospheres strongly suggest an important role for autophagy, or more precisely, ATG4A in breast CSC maintenance. As it was demonstrated here, inhibition of ATG4A led to reduction of a sub-population with CSC properties (Figure 5A). Moreover, the enrichment of this subpopulation during sphere formation was almost completely prevented by ATG4A inhibition (Figure $5 \mathrm{~B}$ ). Furthermore, ATG4A levels influenced size (Figure $3 C$ ) and numbers of mammospheres formed from breast cancer cell lines of the luminal and, even stronger, the basal type (Figure 3B and 3E). Last, modulation of ATG4A expression affected 
the tumourigenicity of SUM-149 cells under physiological conditions in the mammary fat pad of NSG mice (Figure 6A) as well as the composition of resulting tumours (Figure 6B). These results clearly demonstrate that ATG4A is involved in carcinogenesis and the maintenance of cells with a CSC phenotype.

\section{Conclusion}

In order to develop targeted CSC therapies, it is essential to understand the underlying molecular mechanisms of CSC maintenance. To study those mechanisms, we developed a high-throughput negative selection RNAi screening system and provide evidence that it is suitable to identify genes which, like ATG4A, are involved in the maintenance of cells with CSC properties. Analysis of additional cell lines using the described approach should greatly accelerate the search for novel molecular targets that could be used to tackle the cancer stem cell.

\section{Additional files}

Additional file 1: Table S1. Read-count ratios. Read-count ratios from 27,500 shRNA expression constructs.

Additional file 2: Table S2. Average and significance for each gene. Average impact on sphere formation with corresponding $P$-values for all genes.

Additional file 3: Table S3. Signalling pathway enrichment RNAi screen. Pathway enrichment analysis of genes identified via mammosphere formation RNAi screen.

Additional file 4: Table S4. Signalling pathway enrichment expression profile. Pathway enrichment analysis of genes differentially expressed between adherently cultured cells versus mammospheres.

\section{Abbreviations}

BCA: Bicinchoninic acid; CSC: Cancer stem cell; DMEM: Dulbecco's modified eagle's medium; EDTA: Ethylenediaminetetraacetic acid; EMT: Epithelial-mesenchymal transition; FACS: Fluorescence activated cell sorting; GAPDH: Glyceraldehyde-3-phosphate dehydrogenase; H\&E: Hematoxylin and eosin; IL: Interleukin; JAK: Janus kinase; KEGG: Kyoto encyclopedia of genes and genomes; MOI: Multiplicity of infection; NSG: NOD SCID gamma; PBS: Phosphate-buffered saline; RT-PCR: Reverse transcription polymerase chain reaction; shRNAi: Short hairpin RNA interference; S-P: Sub-population; STAT: Signal transducers and activators of transcription.

\section{Competing interests}

The authors declare that they have no competing interests.

\section{Authors' contributions}

JW optimised RNAi screening conditions, conducted RNAi screens, performed or participated in all experiments and their analysis, and drafted the manuscript. DLD participated in and performed the validation experiments of ATG4A. JF assisted in the data analysis. KMD performed the xenotransplantation experiments and completed the tissue staining. CF evaluated the immunohistochemical staining. JDH participated in the design of the study and in writing the manuscript. MB designed the study, supervised the experiments and drafted the manuscript. All authors read and approved the final manuscript.

\section{Acknowledgements}

This work was supported by a grant of the DKFZ intramural funding programme awarded to MB and a DKFZ PhD scholarship awarded to JW. Lentiviral shRNA libraries were kindly provided and developed by Cellecta based on NIH-funded research grant support 44RR024095, 44HG003355.
Financial support by the German Federal Ministry of Education and Research (BMBF) as part of the PaCaNet consortium is gratefully acknowledged.

\section{Author details}

${ }^{1}$ Division of Functional Genome Analysis, Deutsches Krebsforschungszentrum, Heidelberg, Germany. ${ }^{2}$ Core Facility Tumor Models, Deutsches Krebsforschungszentrum, Heidelberg, Germany. ${ }^{3}$ Institute of Pathology, University Hospital, Heidelberg, Germany.

\section{Received: 4 March 2013 Accepted: 31 October 2013}

Published: 14 November 2013

\section{References}

1. Marusyk A, Polyak K: Tumor heterogeneity: causes and consequences. Biochim Biophys Acta 2010, 1805:105-117.

2. Sarrio D, Franklin CK, Mackay A, Reis-Filho JS, Isacke CM: Epithelial and mesenchymal subpopulations within normal basal breast cell lines exhibit distinct stem cell/progenitor properties. Stem Cells 2012, 30:292-303

3. Honeth G, Bendahl PO, Ringner M, Saal LH, Gruvberger-Saal SK, Lovgren K, Grabau D, Ferno M, Borg A, Hegardt C: The CD44+/CD24- phenotype is enriched in basal-like breast tumors. Breast Cancer Res 2008, 10:R53.

4. Shipitsin M, Campbell LL, Argani P, Weremowicz S, Bloushtain-Qimron N, Yao J, Nikolskaya T, Serebryiskaya T, Beroukhim R, Hu M, Halushka MK, Sukumar S, Parker LM, Anderson KS, Harris LN, Garber JE, Richardson AL, Schnitt SJ, Nikolsky Y, Gelman RS, Polyak K: Molecular definition of breast tumor heterogeneity. Cancer Cell 2007, 11:259-273.

5. Fillmore $\mathrm{CM}$, Kuperwasser $\mathrm{C}$ : Human breast cancer cell lines contain stem-like cells that self-renew, give rise to phenotypically diverse progeny and survive chemotherapy. Breast Cancer Res 2008, 10:R25.

6. Al-Hajj M, Wicha MS, Benito-Hernandez A, Morrison SJ, Clarke MF: Prospective identification of tumorigenic breast cancer cells. Proc Natl Acad Sci USA 2003 100:3983-3988.

7. Chaffer $\mathrm{CL}$, Weinberg RA: A perspective on cancer cell metastasis. Science 2011, 331:1559-1564.

8. Sheridan C, Kishimoto H, Fuchs RK, Mehrotra S, Bhat-Nakshatri P, Turner CH, Goulet R Jr, Badve S, Nakshatri H: CD44+/CD24- breast cancer cells exhibit enhanced invasive properties: an early step necessary for metastasis. Breast Cancer Res 2006, 8:R59.

9. Li X, Lewis MT, Huang J, Gutierrez C, Osborne CK, Wu MF, Hilsenbeck SG, Pavlick A, Zhang X, Chamness GC, Wong H, Rosen J, Chang JC: Intrinsic resistance of tumorigenic breast cancer cells to chemotherapy. J Natl Cancer Inst 2008, 100:672-679.

10. Sarrio D, Rodriguez-Pinilla SM, Hardisson D, Cano A, Moreno-Bueno G, Palacios J: Epithelial-mesenchymal transition in breast cancer relates to the basal-like phenotype. Cancer Res 2008, 68:989-997.

11. Thiery JP, Acloque H, Huang RY, Nieto MA: Epithelial-mesenchymal transitions in development and disease. Cell 2009, 139:871-890.

12. May CD, Sphyris N, Evans KW, Werden SJ, Guo W, Mani SA: Epithelialmesenchymal transition and cancer stem cells: a dangerously dynamic duo in breast cancer progression. Breast Cancer Res 2011, 13:202.

13. Mani SA, Guo W, Liao MJ, Eaton EN, Ayyanan A, Zhou AY, Brooks M, Reinhard F, Zhang CC, Shipitsin M, Campbell LL, Polyak K, Brisken C, Yang J, Weinberg RA: The epithelial-mesenchymal transition generates cells with properties of stem cells. Cell 2008, 133:704-715.

14. Creighton CJ, Li X, Landis M, Dixon JM, Neumeister VM, Sjolund A, Rimm DL, Wong H, Rodriguez A, Herschkowitz JI, Fand C, Zhanga X, Hec X, Pavlicka A, Gutierreza MC, Renshawb L, Larionovb AA, Faratianb D, Hilsenbecka SG, Peroud CM, Lewisa MT, Rosena JM, Chang JC: Residual breast cancers after conventional therapy display mesenchymal as well as tumor-initiating features. Proc Natl Acad Sci USA 2009, 106:13820-13825.

15. Micalizzi DS, Farabaugh SM, Ford HL: Epithelial-mesenchymal transition in cancer: parallels between normal development and tumor progression. J Mammary Gland Biol Neoplasia 2010, 15:117-134.

16. Cardiff RD, Couto S, Bolon B: Three interrelated themes in current breast cancer research: gene addiction, phenotypic plasticity, and cancer stem cells. Breast Cancer Res 2011, 13:216.

17. Dontu G, Abdallah WM, Foley JM, Jackson KW, Clarke MF, Kawamura MJ, Wicha MS: In vitro propagation and transcriptional profiling of human mammary stem/progenitor cells. Genes Dev 2003, 17:1253-1270. 
18. Ponti D, Costa A, Zaffaroni N, Pratesi G, Petrangolini G, Coradini D, Pilotti S, Pierotti MA, Daidone MG: Isolation and in vitro propagation of tumorigenic breast cancer cells with stem/progenitor cell properties. Cancer Res 2005, 65:5506-5511.

19. Guttilla IK, Phoenix KN, Hong X, Tirnauer JS, Claffey KP, White BA: Prolonged mammosphere culture of MCF-7 cells induces an EMT and repression of the estrogen receptor by microRNAs. Breast Cancer Res Treat 2012, 132:75-85.

20. The DECIPHER Open Source RNAi Screening Project: [http://www. decipherproject.net/]

21. da Huang W, Sherman BT, Lempicki RA: Systematic and integrative analysis of large gene lists using DAVID bioinformatics resources. Nat Protoc 2009, 4:44-57.

22. ArrayExpress: http://www.ebi.ac.uk/arrayexpress/.

23. Gupta PB, Fillmore CM, Jiang G, Shapira SD, Tao K, Kuperwasser C, Lander ES: Stochastic state transitions give rise to phenotypic equilibrium in populations of cancer cells. Cell 2011, 146:633-644.

24. Wells A, Yates C, Shepard CR: E-cadherin as an indicator of mesenchymal to epithelial reverting transitions during the metastatic seeding of disseminated carcinomas. Clin Exp Metastasis 2008, 25:621-628.

25. Mendez MG, Kojima S, Goldman RD: Vimentin induces changes in cell shape, motility, and adhesion during the epithelial to mesenchymal transition. FASEB J 2010, 24:1838-1851.

26. Drasin DJ, Robin TP, Ford HL: Breast cancer epithelial-to-mesenchymal transition: examining the functional consequences of plasticity. Breast Cancer Res 2011, 13:226.

27. Lacroix M, Leclercq G: Relevance of breast cancer cell lines as models for breast tumours: an update. Breast Cancer Res Treat 2004 83:249-289.

28. Leek RD, Landers RJ, Harris AL, Lewis CE: Necrosis correlates with high vascular density and focal macrophage infiltration in invasive carcinoma of the breast. Br J Cancer 1999, 79:991-995.

29. Balkwill F, Charles KA, Mantovani A: Smoldering and polarized inflammation in the initiation and promotion of malignant disease. Cancer Cell 2005, 7:211-217.

30. Mantovani A, Allavena P, Sica A, Balkwill F: Cancer-related inflammation. Nature 2008, 454:436-444.

31. Bruna A, Greenwood W, Le Quesne J, Teschendorff A, Miranda-Saavedra D, Rueda OM, Sandoval JL, Vidakovic AT, Saadi A, Pharoah P, Stingl J, Caldas $C$ : TGFbeta induces the formation of tumour-initiating cells in claudinlow breast cancer. Nat Commun 2012, 3:1055.

32. Liu S, Wicha MS: Targeting breast cancer stem cells. J Clin Oncol 2010, 28:4006-4012

33. Korkaya H, Liu S, Wicha MS: Breast cancer stem cells, cytokine networks, and the tumor microenvironment. J Clin Invest 2011, 121:3804-3809.

34. Marotta LL, Almendro V, Marusyk A, Shipitsin M, Schemme J, Walker SR, Bloushtain-Qimron N, Kim JJ, Choudhury SA, Maruyama R, Wu Z, Gönen M, Mulvey LA, Bessarabova MO, Huh SJ, Silver SJ, Kim SY, Park SY, Lee HE, Anderson KS, Richardson AL, Nikolskaya T, Nikolsky Y, X. Liu S, Root DE, Hahn WC, Frank DA, Polyak K: The JAK2/STAT3 signaling pathway is required for growth of CD44(+)CD24(-) stem cell-like breast cancer cells in human tumors. J Clin Invest 2011, 121:2723-2735.

35. Hernandez-Vargas H, Ouzounova M, Le Calvez-Kelm F, Lambert MP McKay-Chopin S, Tavtigian SV, Puisieux A, Matar C, Herceg Z: Methylome analysis reveals Jak-STAT pathway deregulation in putative breast cancer stem cells. Epigenetics 2011, 6:428-439.

36. Dave B, Landis MD, Tweardy DJ, Chang JC, Dobrolecki LE, Wu MF, Zhang X, Westbrook TF, Hilsenbeck SG, Liu D, Lewis MT, Tweardy DJ, Chang JC: Selective small molecule Stat3 inhibitor reduces breast cancer tumorinitiating cells and improves recurrence free survival in a humanxenograft model. Plos One 2012, 7:e30207.

37. Gurusamy N, Das DK: Autophagy, redox signaling, and ventricular remodeling. Antioxid Redox Signal 2009, 11:1975-1988.

38. Chen N, Karantza-Wadsworth V: Role and regulation of autophagy in cancer. Biochim Biophys Acta 2009, 1793:1516-1523.

39. Cufi S, Vazquez-Martin A, Oliveras-Ferraros C, Martin-Castillo B, Vellon L, Menendez JA: Autophagy positively regulates the CD44(+) CD24(-/low) breast cancer stem-like phenotype. Cell Cycle 2011, 10:3871-3885.

40. Gong C, Bauvy C, Tonelli G, Yue W, Delomenie C, Nicolas V, Zhu Y, Domergue V, Marin-Esteban V, Tharinger H, Delbos L, Gary-Gouy H, Morel A-P, Ghavami S, Song E, Codogno P, Mehrpour M: Beclin 1 and autophagy are required for the tumorigenicity of breast cancer stem-like/progenitor cells. Oncogene 2013, 32:2261-2272.

41. Berardi DE, Campodonico PB, Diaz Bessone MI, Urtreger AJ, Todaro LB: Autophagy: friend or foe in breast cancer development, progression, and treatment. Int J Breast Cancer 2011, 2011:595092.

42. Vessoni AT, Muotri AR, Okamoto OK: Autophagy in stem cell maintenance and differentiation. Stem Cells Dev 2012, 21:513-520.

43. Gong $C$, Song $E_{1}$ Codogno , Mehrpour M: The roles of BECN1 and autophagy in cancer are context dependent. Autophagy 2012, 8:12.

44. Scherz-Shouval R, Shvets E, Fass E, Shorer H, Gil L, Elazar Z: Reactive oxygen species are essential for autophagy and specifically regulate the activity of Atg4. EMBO J 2007, 26:1749-1760.

45. Marino G, Lopez-Otin C: Autophagy: molecular mechanisms, physiological functions and relevance in human pathology. Cell Mol Life Sci 2004, 61:1439-1454

46. Yu ZQ, Ni T, Hong B, Wang HY, Jiang FJ, Zou S, Chen Y, Zheng XL, Klionsky DJ, Liang $Y$, Xie Z: Dual roles of Atg8-PE deconjugation by Atg4 in autophagy. Autophagy 2012, 8:883-892.

47. Nair U, Yen WL, Mari M, Cao Y, Xie Z, Baba M, Reggiori F, Klionsky DJ: A role for Atg8-PE deconjugation in autophagosome biogenesis. Autophagy 2012, 8:780-793.

doi:10.1186/bcr3576

Cite this article as: Wolf et al:: A mammosphere formation RNAi screen reveals that ATG4A promotes a breast cancer stem-like phenotype. Breast Cancer Research 2013 15:R109.

\section{Submit your next manuscript to BioMed Central and take full advantage of:}

- Convenient online submission

- Thorough peer review

- No space constraints or color figure charges

- Immediate publication on acceptance

- Inclusion in PubMed, CAS, Scopus and Google Scholar

- Research which is freely available for redistribution

Submit your manuscript at www.biomedcentral.com/submit
C Biomed Central 